Original Research Paper

\title{
Relationship between Streptococcus gallolyticus Infective Endocarditis and Pre-Neoplastic Colorectal Lesions
}

\author{
${ }^{1}$ Pau Vilardell, ${ }^{1}$ Sergio Moral, ${ }^{1}$ Josep Maria Frigola, ${ }^{1}$ Manel Morales, ${ }^{2}$ Esther Ballesteros, \\ ${ }^{3}$ Xavier Salgado, ${ }^{3}$ Antoni Castro, ${ }^{2}$ Antoni Rubió, ${ }^{1}$ Marc Abulí and ${ }^{1,4,5}$ Ramon Brugada \\ ${ }^{I}$ Department of Cardiology, Hospital Universitari Doctor Josep Trueta, CIBER-CV (Girona, Spain), Spain \\ ${ }^{2}$ Dirección Territorial de Radiologia i Medicina Nuclear de Girona. IDI. IDIBGI (Girona, Spain), Spain \\ ${ }^{3}$ Department of Internal Medicine, Hospital Universitari Doctor Josep Trueta (Girona, Spain), Spain \\ ${ }^{4}$ Cardiovascular Genetics Centre, University of Girona-IDIBGI; Department of Medical Science, \\ School of Medicine, University of Girona, Girona, Spain \\ ${ }^{5}$ Centro Investigación Biomédica en Red: Enfermedades Cardiovasculares (CIBERCV), Madrid, Spain
}

Article history

Received: 15-04-2021

Revised: 14-05-2021

Accepted: 20-05-2021

Corresponding Author:

Pau Vilardell

Department of Cardiology,

Hospital Universitari Doctor

Josep Trueta, CIBER-CV

(Girona, Spain). Spain

Email: pau.vilardell.rigau@gmail.com

\begin{abstract}
Colorectal cancer is associated with Infective Endocarditis (IE) due to specific gut pathogens, such as Streptococcus gallolyticus subspecies, that use tumor presence as a point of blood entry. However, the association between Streptococcus gallolyticus related IE and pre-cancerous colorectal lesions like dysplastic adenomas is unclear. Seventy-one patients diagnosed with IE who underwent colonoscopy in the extension study during admission were included in a clinical, microbiological and imaging follow-up, between January 2008 and December 2020. Pre-cancerous lesions were divided as high and low-grade dysplasia based on World Health Organization criteria. Colorectal cancer was defined as the presence of malignant cell beyond the muscularis mucosa. Twenty-two IE patients $(31 \%)$ presented colorectal lesions: $8(36 \%)$ colorectal cancer and $14(64 \%)$ pre-cancerous lesions [14\% high degree $(n=2) ; 86 \%$ low degree $(n=12)]$. Both, colorectal cancer $(25 \%$ Vs $2 \%$; $\mathrm{p}=0.007)$ and pre-neoplastic lesions $(50 \%$ Vs $2 \% ; \mathrm{p}<0.001)$ were related with higher prevalence of IE caused by Streptococcus gallolyticus. Additionally, the subgroup of low grade precancerous lesions also showed this association $(50 \%$ Vs $2 \%$; $<<0.001)$. Precancerous colorectal lesions are associated with Streptococcus gallolyticus IE. These results suggest that high and low degree colorectal lesions may also act as a gateway for gut pathogens.
\end{abstract}

Keywords: Infective Endocarditis, Colorectal Cancer, Streptococcus gallolyticus, Gut Pathogens

\section{Introduction}

Infective Endocarditis (IE) due to gut pathogens presents a well-recognized relationship with Colorectal Cancer (CRC) (McCoy and Mason 3rd, 1951; Klein et al., 1977; Gupta et al., 2010; Darjee and Gibb, 1993). Streptococcus gallolyticus (previously Streptococcus bovis) is the most relevant microorganism of gut microbiota involved in patients with underlying occult CRC (Schlegel et al., 2003; Giannitsioti et al., 2007; Corredoira et al., 2008). Emerging studies revealed that $65 \%$ of patients diagnosed with Streptococcus gallolyticus IE had a concomitant CRC (Hensler, 2011; Pasquereau-Kotula et al., 2018) and stablished that patients with Streptococcus gallolyticus bacteriemia had 5-fold more CRC (Amado et al., 2015; Takamura et al., 2014). It is usually located in the colonic wall and it could benefit from the presence of a tumor and use these neoplastic sites as a point of entry to cause systemic infections (Boleij and Tjalsma, 2013). The degree of bowel wall involvement that could allow the entry of gut pathogens and, therefore greater IE risk, is unknown. In the setting of Streptococcus gallolyticus IE, it is recommended to rule out occult CRC with colonoscopy during hospitalization (Schreuders et al., 2015; Habib et al., 2015). However, it is still a debate of which colorectal lesions could become the point of entry to cause IE.

The most frequent pre-neoplastic colorectal lesions are colonic adenomas, slow overgrowths of the colonic mucosa that carry a risk of becoming malignant. They are 
classified as flat, sessile or pedunculated, being the adenoma size the most important carcinogenic potential marker (Lemaire et al., 2017; Lieberman et al., 2008; Ferlitsch et al., 2011). Colonic adenomas are much more prevalent than CRC lesions, being identified in $\sim 40 \%$ of asymptomatic population over 60 years old (Strum, 2016). Multiple hypotheses suggest that Streptococcus gallolyticus may play an etiological role in cancer development (Boleij and Tjalsma, 2013). However, whether the association of gut pathogens related to IE with colorectal lesions is a consequence of the gastrointestinal lesion or could promote CRC is not well-known. Additionally, it is not established if lower degree dysplastic colorectal lesions could also be associated with systemic entry of gut microorganisms. Since only $44 \%$ of IE have an identified portal of entry, pre-cancerous lesions could be the gateway for Streptococcus gallolyticus in some of these cases (Delahaye et al., 2016; Murdoch et al., 2009; Habib et al., 2019).

The aim of this study was to determine the relationship between pre-neoplastic colorectal lesions (high and lowgrade dysplasia) and Streptococcus gallolyticus IE, evaluating those IE cases in which a colonoscopy was performed in the extension study during admission.

\section{Materials and Methods}

\section{Study Design}

An observational retrospective single-center study was conducted through data gathering from electronic medical records covering the period from January 2008 to December 2020. Patients with IE diagnosis, baseline Transthoracic Echocardiogram (TTE) and a colonoscopy performed for the IE extension analysis during the event were included. All patients were diagnosed of IE according modified Duke Criteria (Li et al., 2000) and those with only a suspected diagnosis of the illness without confirmation were excluded. Patients were treated during the hospitalization according to European current guidelines (Habib et al., 2015). The Endocarditis Team of our institution decided the multidisciplinary approach in the diagnostic and therapeutic management of all IE patients included. The ethical committee of our institution approved the study. Finally, from 402 patients diagnosed with IE, 71 (18\%) underwent a screening colonoscopy during hospitalization and fulfilled all the inclusion criteria (Fig. 1).

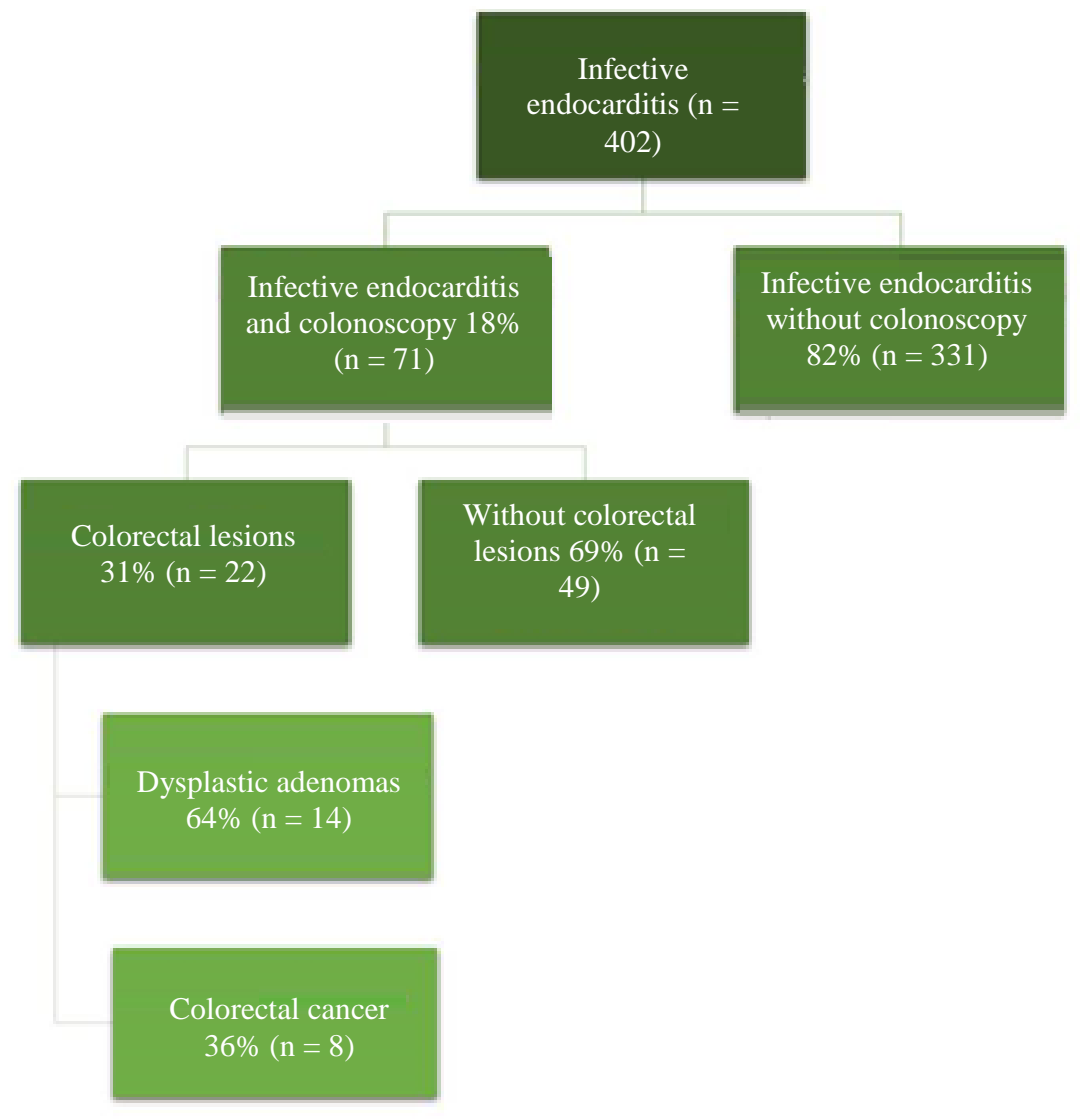

Fig. 1: Distribution of the study population 
Table 1: Colorectal lesions classification based on World Health Organization

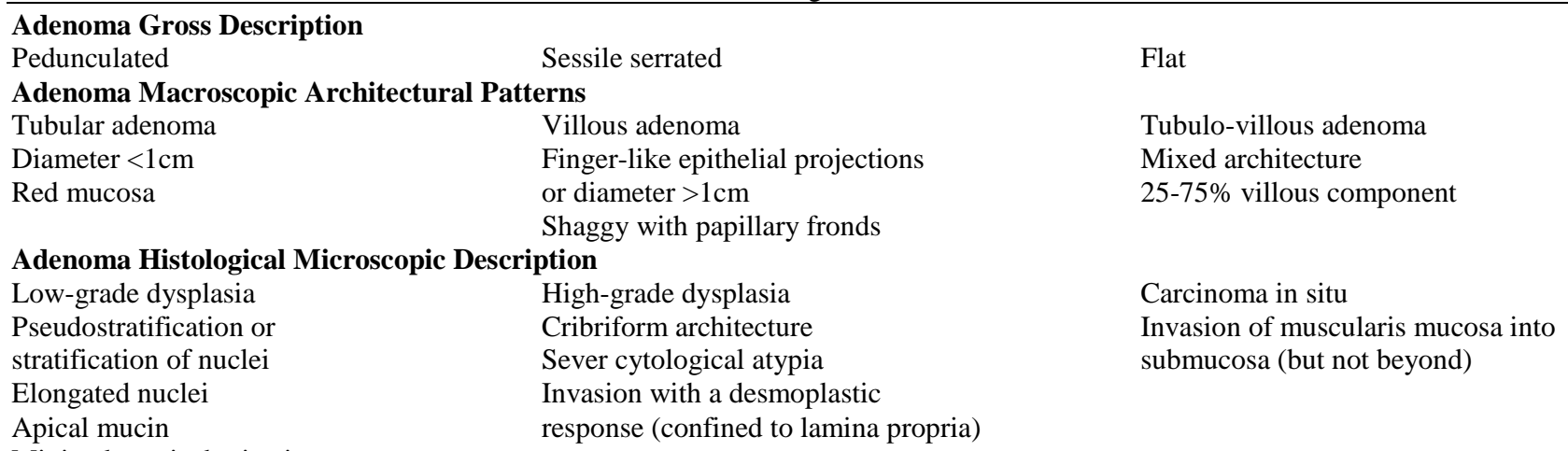

Minimal atypical mitosis

\section{CRC Definition}

Glandular neoplasm of the colorectum.

By definition, the presence of malignant cells beyond the muscularis mucosa

\section{$\mathrm{CRC}=$ Colorectal Cancer}

\section{IE Variables}

Each patient was analyzed with the same protocol searching data in medical records, starting on the day of hospital admission. Demographic, clinical and microbiological parameters were collected of all cases. Patients underwent a baseline comprehensive TTE with commercially available instruments (Phillips Medical Systems, Bothell, Washington and General Electric Medical Systems, Milwaukee, Wisconsin) as part of a standard clinical diagnostic evaluation. Measurements and recordings were obtained according to current recommendations (Lang et al., 2015). Left ventricular ejection fraction was calculated using the Simpson biplane method. A semiquantitative 4-point scale (with grades of none, mild, moderate and severe) was applied to stratify valvular regurgitation on color 2D Doppler echocardiography clips obtained in multiple standard views. A Transesophageal Echocardiography (TEE) and/or 18FFDG Positron Emission Tomography/Computed Tomography (18F-FDG PET/CT) were performed according to Endocarditis Team management. Similar data was recorded on follow-up TTE during hospitalization, which was performed as part of clinical follow-up. Data on death and survival were obtained from medical records.

\section{Colorectal Lesions Variables}

Data from performed colonoscopies to analyze the origin of IE were collected during admission. Endoscopic findings described in histopathological reports classified the colorectal pre-neoplastic lesions as followed: Tubular adenoma was defined as an adenoma with a diameter of $<1 \mathrm{~cm}$ and villous adenoma was defined as finger-like epithelial projections or an adenoma diameter of $>1 \mathrm{~cm}$. Carcinoma in situ was classified as an adenoma with high-grade dysplasia. High-grade dysplasia is characterized by any one of the following: Cribriform architecture, severe cytological atypia and invasion with a desmoplastic response (invasion confined to the lamina propria) based on the histological classification of World Health Organization (Table 1) (Jass and Sobin, 1989). Those patients without all previous cited criteria were considered adenoma with low-grade dysplasia. The criterion for CRC was the presence of malignant cells beyond the muscularis mucosa. Nonneoplastic colonic diseases were also collected.

\section{Statistical Analysis}

The results were presented as mean \pm standard deviation for the continuous variables normally distributed, medians for the continuous variables of nonGaussian distribution and percentages for the categorical variables. The characteristics of patients were compared using the $\mathrm{X}^{2}$ or Fisher exact test for the categorical variables. The quantitative variables were analyzed using the ANOVA test, in case of normal distribution, or the Kruskal-Wallis test in case of non-normal distribution. The level of significance was set at $p<0.05$. The statistical analysis was performed using SPSS version 20.0 (SPSS Inc.; Chicago, Illianois, US).

\section{Results}

Seventy-one patients with IE underwent to colonoscopy as a part of the extension analysis during hospitalization (mean time \pm SD: $13 \pm 7$ days): 49 patients $(69 \%)$ presented IE without colorectal lesions, 14 patients (20\%) were IE with dysplastic adenomas and 8 patients (11\%) were IE with CRC. All lesions were removed during the colonoscopic procedure for histopathological analysis. The 14 dysplastic adenomas were histologically classified in two groups: High-degree $(n=2 ; 14 \%)$ and low-degree $(n=12 ; 86 \%)$ of dysplasia. Additionally, dysplastic adenomas were macroscopically divided in villous $(n=9 ; 64 \%)$ and tubular $(n=5 ; 36 \%)$ adenomas. 
Baseline Characteristics, Clinical Presentation and Echocardiographic Results According to Colonoscopy Findings

The study population was mainly men $(71 \%)$ with a mean age of $69 \pm 15$ years. Only 9 patients $(13 \%)$ had an identified portal of entry: Intravascular catheter $(n=4)$, haemodialysis $(=2)$, urinary origin $(\mathrm{n}=2)$ and dental procedure $(\mathrm{n}=1)$. From 62 patients without clear portal of entry, 20 of them (32\%) showed colorectal lesions: 13 patients $(65 \%)$ were pre-cancerous lesions and 7 $(35 \%)$ were CRC. There were no significant differences in baseline characteristics between all groups (Table 2). A total of 68 patients $(96 \%)$ debuted with fever and only 15 cases $(21 \%)$ presented shortness of breath.

Table 2: Basal characteristics, clinical presentation, analytical parameters, cardiac imaging findings, microbiology and clinical outcomes of groups according to colonoscopy findings

\begin{tabular}{|c|c|c|c|c|}
\hline Variables $(\mathrm{n}=71)$ & $\begin{array}{l}\text { IE without colorectal } \\
\text { lesions }(n=49)\end{array}$ & $\begin{array}{l}\text { IE and dysplastic } \\
\text { adenomas }(n=14)\end{array}$ & $\begin{array}{l}\text { IE and CRC } \\
(\mathrm{n}=8)\end{array}$ & p-value \\
\hline \multicolumn{5}{|l|}{ Basal Characteristics } \\
\hline Gender (males; n (\%)) & $35(71)$ & $9(64)$ & $7(87)$ & 0.18 \\
\hline Age (years; mean \pm SD) & $65 \pm 18$ & $69 \pm 13$ & $68 \pm 23$ & 0.89 \\
\hline Hypertension, $\mathrm{n}(\%)$ & $23(47)$ & $9(64)$ & $5(63)$ & 0.29 \\
\hline Diabetes mellitus, n (\%) & $18(37)$ & $4(29)$ & $3(37)$ & 0.61 \\
\hline Previous pacemaker, n (\%) & $11(20)$ & $0(0)$ & $0(0)$ & 0.14 \\
\hline Previous neoplasm, n (\%) & $5(10)$ & $2(14)$ & $2(25)$ & 0.78 \\
\hline Native left-sided IE, n (\%) & $28(57)$ & $11(79)$ & $7(88)$ & 0.25 \\
\hline Prosthetic left-sided IE, n (\%) & $11(22)$ & $3(21)$ & $0(0)$ & 0.73 \\
\hline Portal of entry, $\mathrm{n}(\%)$ & $7(14)$ & $1(7)$ & $1(13)$ & 0.54 \\
\hline Charlson Index (mean \pm SD) & $2.5 \pm 1$ & $3 \pm 1$ & $3 \pm 2$ & 0.62 \\
\hline Euroscore II (mean \pm SD) & $13 \pm 9$ & $12 \pm 7$ & $11 \pm 8$ & 0.90 \\
\hline \multicolumn{5}{|c|}{ Clinical Presentation and Analytic Parameters } \\
\hline Fever, $\mathrm{n}(\%)$ & $48(98)$ & $13(93)$ & $7(87)$ & 0.17 \\
\hline Dyspnoea, n (\%) & $9(18)$ & $5(36)$ & $1(13)$ & 0.58 \\
\hline Abdominal symptoms, $\mathrm{n}(\%)$ & $8(16)$ & $1(7)$ & $1(13)$ & 0.42 \\
\hline Haemoglobin $(\mathrm{mg} / \mathrm{dL} ;$ mean $\pm \mathrm{SD})$ & $11 \pm 2$ & $10 \pm 2$ & $11 \pm 2$ & 0.93 \\
\hline Haematocrit $($ mean \pm SD) & $33 \pm 5$ & $30 \pm 5$ & $35 \pm 5$ & 0.72 \\
\hline Leucocytes $\left(10^{6} / \mathrm{L} ;\right.$ mean $\left.\pm \mathrm{SD}\right)$ & $11.919 \pm 4.253$ & $9.728 \pm 4.521$ & $12.795 \pm 5.1853$ & 0.62 \\
\hline $\mathrm{CRP}(\mathrm{mg} / \mathrm{dL} ;$ mean $\pm \mathrm{SD})$ & $10 \pm 8$ & $11 \pm 8$ & $16 \pm 11$ & 0.78 \\
\hline Creatinine $(\mathrm{mg} / \mathrm{dL}$; mean $\pm \mathrm{SD})$ & $1.3 \pm 1.1$ & $0.9 \pm 0.3$ & $1.4 \pm 0.6$ & 0.54 \\
\hline \multicolumn{5}{|l|}{ Cardiac Imaging Findings } \\
\hline \multicolumn{5}{|l|}{ Location } \\
\hline Aortic valve, n (\%) & $11(22)$ & $4(29)$ & $3(37)$ & 0.40 \\
\hline Mitral valve, n (\%) & $17(35)$ & $7(50)$ & $4(50)$ & 0.22 \\
\hline Prosthetic valve, n (\%) & $11(22)$ & $3(21)$ & $0(0)$ & 0.39 \\
\hline Right sided, n $(\%)$ & $10(20)$ & $0(0)$ & $1(13)$ & 0.17 \\
\hline Major vegetation diameter $(\mathrm{mm}$; mean $\pm \mathrm{SD})$ & $13 \pm 6$ & $15 \pm 8$ & $17 \pm 7$ & 0.50 \\
\hline $\operatorname{LVEF}(\% ;$ mean $\pm \mathrm{SD})$ & $57 \pm 11$ & $60 \pm 6$ & $57 \pm 11$ & 0.94 \\
\hline TAPSE $(\mathrm{mm} ;$ mean $\pm \mathrm{SD})$ & $20 \pm 2$ & $19 \pm 3$ & $20 \pm 2$ & 0.91 \\
\hline Perivalvular abscess, n (\%) & $6(12)$ & $0(0)$ & $1(10)$ & 0.15 \\
\hline Leaflet perforation, $\mathrm{n}(\%)$ & $1(2)$ & $0(0)$ & $2(20)$ & 0.19 \\
\hline \multicolumn{5}{|l|}{ Microbiology } \\
\hline Staphylococcus aureus, n (\%) & $14(29)$ & $1(7)$ & $0(0)$ & 0.10 \\
\hline Streptococcus epidermidis, n (\%) & $11(22)$ & $1(7)$ & $1(12)$ & 0.18 \\
\hline Enterococcus faecalis, n (\%) & $6(12)$ & $3(21)$ & $2(25)$ & 0.74 \\
\hline Streptococcus viridians, $\mathrm{n}(\%)$ & $3(6)$ & $2(13)$ & $1(12)$ & 0.49 \\
\hline Streptococcus gallolyticus, n (\%) & $1(2)$ & $7(50)$ & $2(25)$ & $<0.001$ \\
\hline Escherichia coli, n (\%) & $2(4)$ & $0(0)$ & $0(0)$ & 0.96 \\
\hline Streptococcus agalactiae, n (\%) & $2(4)$ & $0(0)$ & $0(0)$ & 0.85 \\
\hline Other microorganisms, $\mathrm{n}(\%)$ & $9(18)$ & $0(0)$ & $1(12)$ & 0.11 \\
\hline Negative, n (\%) & $1(2)$ & $0(0)$ & $1(12)$ & 0.59 \\
\hline \multicolumn{5}{|l|}{ Clinical Outcomes } \\
\hline In-hospital mortality, n (\%) & $9(18)$ & $5(36)$ & $1(12.5)$ & 0.38 \\
\hline Open-surgery treatment, n (\%) & $22(45)$ & $4(29)$ & $2(25)$ & 0.48 \\
\hline Systemic embolisms, n (\%) & $9(18)$ & $4(29)$ & $1(10)$ & 0.93 \\
\hline Neurological embolisms, n (\%) & $7(14)$ & $1(7)$ & $0(0)$ & 0.31 \\
\hline
\end{tabular}

$\overline{\mathrm{CRC}}=$ Colorectal Cancer; CRP = C-Reactive Protein; IE = Infective Endocarditis; LVEF = Left Ventricular Ejection Fraction; TAPSE $=$ Tricuspid Annular Plane Systolic Excursion 


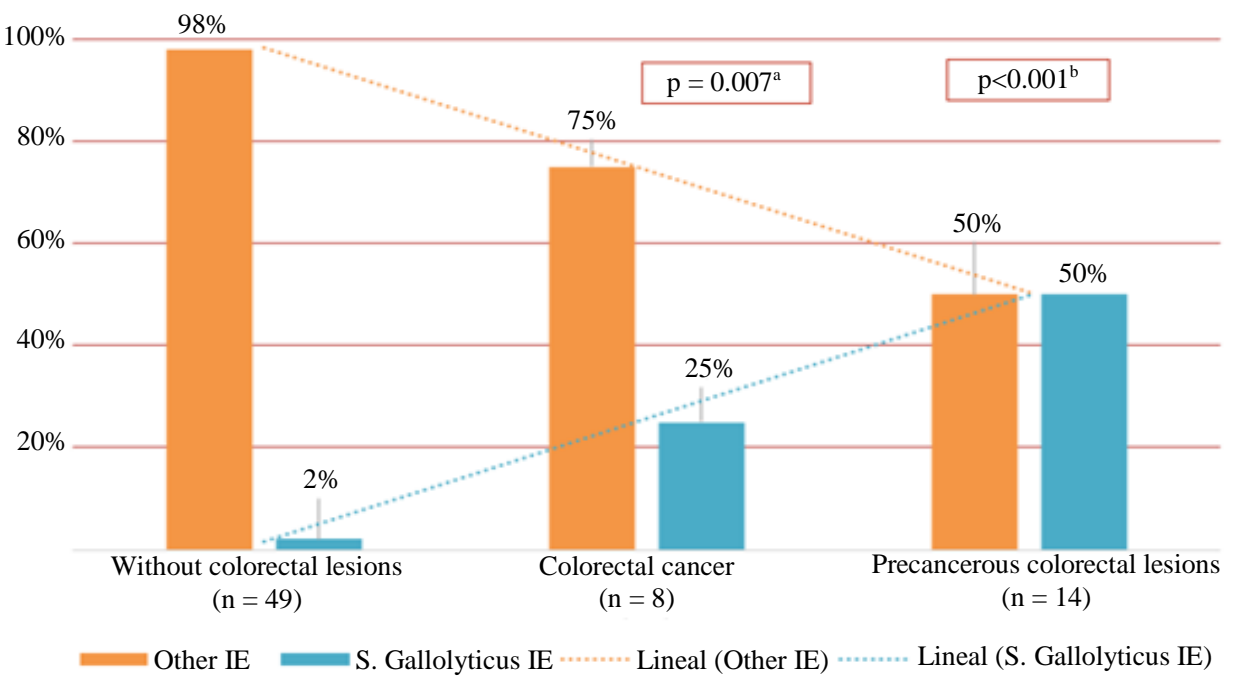

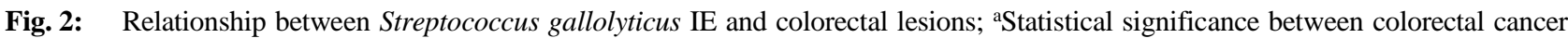
and Streptococcus gallolyticus IE; ${ }^{b}$ Statistical significance between pre-neoplastic colorectal lesions and Streptococcus gallolyticus IE

Ten patients (14\%) showed abdominal symptoms previous to the colonoscopy: 8 cases $(80 \%)$ without colorectal lesions, $1(10 \%)$ with a pre-cancerous colorectal lesion and $1(10 \%)$ with CRC. There were no significant differences between all groups in clinical presentation and analytical parameters at the time of diagnosis. As a part of the extension study, 96\% of patients $(n=68)$ underwent to a TEE and $14 \%(n=10)$ to a 18F-FDG PET/TC during hospitalization. Native mitral valve was the most frequent location $(35 \%, \mathrm{n}=25)$. There were neither statistically significant differences in echocardiographic features between groups (Table 2).

\section{Microbiological Results According to Colonoscopy Findings}

Streptococcus gallolyticus was the third most common microorganism $(14 \% ; \mathrm{n}=10)$ and the most frequent in those with colorectal lesions: $50 \%$ of IE with pre-neoplastic lesions $(\mathrm{n}=7)$ and $25 \%$ of IE with CRC $(\mathrm{n}=2)$. In contrast, only one case $(2 \%)$ without colorectal lesions presented Streptococcus gallolyticus. From 62 patients $(87 \%)$ without clear portal of entry, 10 of them (16\%) presented Streptococcus gallolyticus IE. The relationship between Streptococcus gallolyticus IE and colorectal lesions is

shown in Fig. 2. Both, CRC group (25\% Vs 2\%; p = $0.007)$ and pre-neoplastic lesions group (50\% Vs $2 \%$; $\mathrm{p}<0.001)$ were associated with significant higher incidence of Streptococcus gallolyticus IE. Additionally, the subgroup of cases with low degree pre-cancerous lesions $(n=12)$ was also related to a higher incidence of Streptococcus gallolyticus IE $(\mathrm{n}=6)(50 \%$ Vs $2 \%$; $\mathrm{p}<0.001)$. The most frequent microorganism in all groups was Staphylococcus aureus $(\mathrm{n}=15,21 \%)$.

\section{Clinical Outcomes According to Colonoscopy Findings During Hospitalization}

The mean inpatient stay was $34 \pm 71$ days. A total of 15 patients $(21 \%)$ presented in-hospital mortality and 28 cases $(39 \%)$ required cardiac surgery during the IE event. There were no significant differences in inhospital mortality or treatment by cardiac surgery between the three groups. Fourteen systemic (20\%) and eight central nervous system (11\%) embolisms were reported, without significant differences between groups (Table 2).

\section{Discussion}

This study demonstrates that pre-neoplastic colorectal lesions are associated with IE caused by Streptococcus gallolyticus and even more frequently than CRC. Not only high-degree but also low-degree dysplastic adenomas presented this association. However, colonoscopy findings do not seem to affect the in-hospital prognosis of patients.

\section{Colorectal Lesions and Gut Pathogens Related IE}

The association between Streptococcus gallolyticus IE and pre-cancerous colorectal lesions has not been thoroughly explored to date. Our results revealed a strong relation between streptococcal IE and preneoplastic colorectal lesions, even in those cases with low-grade dysplastic adenomas. Although the relationship between Streptococcus gallolyticus IE and CRC is well-established (Ferrari et al., 2008), the mechanisms underlying this association are not well-known. 


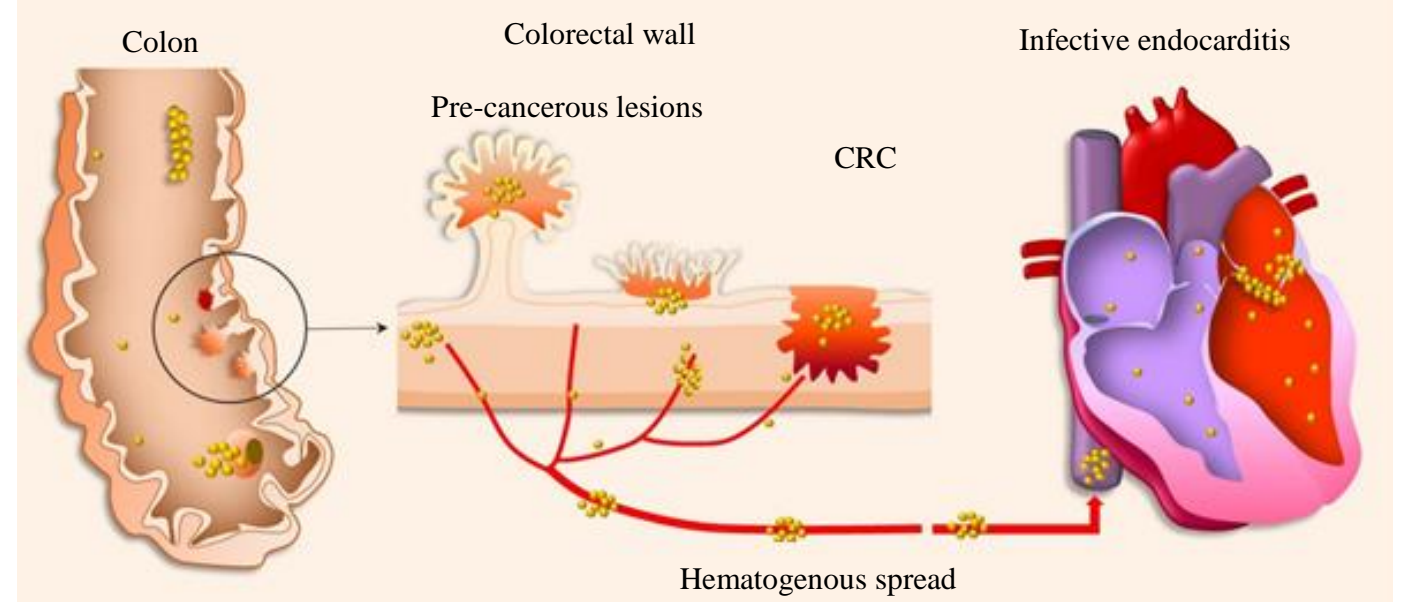

Fig. 3: Hypothetical pathophysiological mechanism for the development of IE caused by gut pathogens. CRC and pre-cancerous lesions are the portal of entry in the itinerary of Streptococcus gallolyticus

Multiple hypotheses suggest that CRC plays an etiological role in Streptococcus gallolyticus IE development: Underlying immunodeficiency, accumulation of mutations, drug-induced or microsatellite instability are some of them. The most plausible pathophysiological explanation could be that CRC acts as a colonic barrier disruption surrounded by an increased expression of collagen IV (distinguished feature of Streptococcus gallolyticus) (Sillanpää et al., 2008; Rusniok et al., 2010). Thus, Streptococcus gallolyticus could have competitive advantage to colonize cancerous sites in the intestine (Fig. 3). Additionally, superior binding to collagen I on heart valves could be responsible for the increased occurrence of Streptococcus gallolyticus IE, compared to other Streptococcus bovis biotypes (Boleij and Tjalsma, 2013). Pre-neoplastic colorectal lesions could also increase collagen IV expression and facilitate systemic infections by Streptococcus gallolyticus with the same mechanism.

\section{Clinical Implications of Association between Pre- Neoplastic Lesions and IE}

Pre-neoplastic colorectal lesions such as colonic adenomas are found in up to $40 \%$ of 60 -year general population and could evolve into CRC by the accumulation of mutations (Strum, 2016; Boleij et al., 2011; Levine and Ahnen, 2006). Although it is necessary to corroborate our hypothesis with larger studies, the fact that these colorectal lesions could act as a gateway for opportunistic gut pathogens, such as Streptococcus gallolyticus, present significant clinical implications. It could be advisable to extend the screening by colonoscopy in all patients with gut pathogens related IE or in those without a clear portal of entry, to rule out occult neoplastic and pre-cancerous colorectal lesions. The colonoscopic screening not only could identify the portal of entry but also detect and eradicate a potential colorectal disease malignancy with clinical implications (Kim et al., 2018; Pericàs et al., 2017). Moreover, in the last years, other advanced imaging techniques, such as 18F-FDG PET/TC, have emerged and may help in the early detection of septic embolisms and occult neoplasms (Pizzi et al., 2015). Furthermore, it would be necessary to analyze the capability of pre-cancerous colorectal lesions for the development of systemic infections and IE risk, in order to carry out preventive strategies and thereby avoid the development of the disease. Finally, patients with highly recurrent or multiple pre-neoplastic lesions may be considered high risk for developing IE due to gut pathogens. Therefore, specific prevention protocols should be considered in these cases.

\section{Limitations}

Our study is a retrospective analysis of a tertiary unicentric cohort with a limited number of patients and therefore the hypothesis stated in this study should be corroborated with larger sample size trials. The lack of uniform microbiological classification of Streptococcus bovis and also the confusing colorectal lesion nomenclature system has led to an underestimation of this relationship during the study period. However, patients included in data analysis were classified from all 3 biotypes of Streptococcus bovis with the latest nomenclature and colorectal lesions were graded from the World Health Organization classification to minimise the impact of these variations (Klein et al., 1977; Gupta et al., 2010; Darjee and Gibb, 1993; Schlegel et al., 2003; Giannitsioti et al., 2007; Corredoira et al., 2008; Jass and Sobin, 1989). Finally, the different techniques employed in the diagnosis of IE and colorectal lesions have evolved significantly during the study period, which could lead to differences between the results obtained in the first cases included compared to the latest ones. 


\section{Conclusion}

Pre-cancerous colorectal lesions are associated with Streptococcus gallolyticus IE. Even low degree dysplastic adenomas present this association. Our results suggest that high and low degree colorectal lesions may act as a gateway for gut pathogens. Hence, it is necessary to rule out occult neoplastic and pre-cancerous colorectal processes in these patients.

\section{Acknowledgment}

The authors are thankful to "Unitat d'Imatge Cardíaca Avançada of Hospital Josep Trueta", for helping us in this original research paper.

\section{Author's Contributions}

Pau Vilardell, Sergio Moral, Esther Ballesteros: Coordinated the data-analysis and contributed to the writing of the manuscript.

Josep Maria Frigola, Manel Morales, Xavier Salgado, Antoni Castro, Antoni Rubió, Marc Abulí and Ramon Brugada: Contributed the writing and reviewing of the manuscript.

\section{Ethics}

This article is original and contains unpublished material. The corresponding author confirms that all of the other authors have read and approved the manuscript and there are no ethical issues involved.

\section{References}

Amado, C., Hidalgo, M. J., Sedano, C., Hebel, A., Porte, L., Braun, S., ... \& Fica, A. (2015). Bacteriemias por Streptococcus gallolyticus (ex S. bovis) y su relación con patología colónica o hepatobiliar y endocarditis. Revista Chilena de Infectología, 32(4), 430-434. https://doi.org/10.4067/S071610182015000500009

Boleij, A., \& Tjalsma, H. (2013). The itinerary of Streptococcus gallolyticus infection in patients with colonic malignant disease. The Lancet Infectious Diseases, 13(8), 719-724. https://doi.org/10.1016/S1473-3099(13)70107-5

Boleij, A., van Gelder, M. M., Swinkels, D. W., \& Tjalsma, H. (2011). Clinical Importance of Streptococcus gallolyticus infection among colorectal cancer patients: systematic review and meta-analysis. Clinical Infectious Diseases, 53(9), 870-878. https://doi.org/10.1093/cid/cir609
Corredoira, J., Alonso, M. P., Coira, A., Casariego, E., Arias, C., Alonso, D., ... \& Varela, J. (2008). Characteristics of Streptococcus bovis endocarditis and its differences with Streptococcus viridans endocarditis. European Journal of Clinical Microbiology \& Infectious Diseases, 27(4), 285-291. https://doi.org/10.1007/s10096-007-0441-y

Darjee, R., \& Gibb, A. P. (1993). Serological investigation into the association between Streptococcus bovis and colonic cancer. Journal of Clinical Pathology, 46(12), 1116-1119. https://doi.org/10.1136/jcp.46.12.1116

Delahaye, F., M'Hammedi, A., Guerpillon, B., de Gevigney, G., Boibieux, A., Dauwalder, O., ... \& Vandenesch, F. (2016). Systematic search for present and potential portals of entry for infective endocarditis. Journal of the American College of Cardiology, 67(2), 151-158. https://doi.org/10.1016/j.jacc.2015.10.065

Ferlitsch, M., Reinhart, K., Pramhas, S., Wiener, C., Gal, O., Bannert, C., ... \& Weiss, W. (2011). Sex-specific prevalence of adenomas, advanced adenomas and colorectal cancer in individuals undergoing screening colonoscopy. JAMA, 306(12), 1352-1358. http://www.saudijgastro.com/text.asp?2014/20/3/15 4/132986.

Ferrari, A., Botrugno, I., Bombelli, E., Dominioni, T., Cavazzi, E., \& Dionigi, P. (2008). Colonoscopy is mandatory after Streptococcus bovis endocarditis: a lesson still not learned. Case report. World Journal of Surgical Oncology, 6(1), 1-5. https://doi.org/10.1186/1477-7819-6-49

Giannitsioti, E., Chirouze, C., Bouvet, A., Béguinot, I., Delahaye, F., Mainardi, J. L., ... \& Association pour l'Etude et la Prévention de l'Endocardite Infectieuse (AEPEI) Study Group. (2007). Characteristics and regional variations of group D streptococcal endocarditis in France. Clinical Microbiology and Infection, 13(8), 770-776. https://doi.org/10.1111/j.1469-0691.2007.01753.x

Gupta, A., Madani, R., \& Mukhtar, H. (2010). Streptococcus bovis endocarditis, a silent sign for colonic tumour. Colorectal Disease, 12(3), 164171. https://doi.org/10.1111/j.14631318.2009.01814.x

Habib, G., Erba, P. A., Iung, B., Donal, E., Cosyns, B., Laroche, C., ... \& Lancellotti, P. (2019). Clinical presentation, aetiology and outcome of infective endocarditis. Results of the ESC-EORP EUROENDO (European infective endocarditis) registry: a prospective cohort study. European Heart Journal, 40(39), 3222-3232.

https://doi.org/10.1093/eurheartj/ehz620 
Habib, G., Lancellotti, P., Antunes, M. J., Bongiorni, M. G., Casalta, J. P., Del Zotti, F., ... \& Zamorano, J. L. (2015). 2015 ESC guidelines for the management of infective endocarditis: the task force for the management of infective endocarditis of the European Society of Cardiology (ESC) endorsed by: European Association for Cardio-Thoracic Surgery (EACTS), the European Association of Nuclear Medicine (EANM). European Heart Journal, 36(44), 3075-3128. https://doi.org/10.1093/eurheartj/ehv319

Hensler, M. E. (2011). Streptococcus gallolyticus, infective endocarditis and colon carcinoma: new light on an intriguing coincidence. Journal of Infectious Diseases, 203(8), 1040-1042. https://doi.org/10.1093/infdis/jiq170

Jass, J., \& Sobin, L. (1989). Histological Typing of Intestinal Tumors. Springer Berlin Heidelberg, ISBN-10: 3540507116.

Kim, K., Kim, D., Lee, S. E., Cho, I. J., Shim, C. Y., \& Hong, G. R. (2018). Infective Endocarditis in Cancer PatientsCausative Organisms, Predisposing Procedures and Prognosis Differ From Infective Endocarditis in NonCancer Patients. Circulation Journal, 83, 452-460. https://doi.org/10.1253/circj.CJ-18-0609

Klein, R. S., Recco, R. A., Catalano, M. T., Edberg, S. C., Casey, J. I., \& Steigbigel, N. H. (1977). Association of Streptococcus bovis with carcinoma of the colon. New England Journal of Medicine, 297(15), 800-802. https://doi.org/10.1056/NEJM197710132971503

Lang, R. M., Badano, L. P., Mor-Avi, V., Afilalo, J., Armstrong, A., Ernande, L., ... \& Voigt, J. U. (2015). Recommendations for cardiac chamber quantification by echocardiography in adults: an update from the American Society of Echocardiography and the European Association of Cardiovascular Imaging. European Heart Journal-Cardiovascular Imaging, 16(3), 233-271. https://doi.org/10.1093/ehjci/jev014

Lemaire, A., Dombrovskiy, V., Saadat, S., Batsides, G., \& Ghaly, A., (2017). Patients with infectious endocarditis and drug dependence have worse clinical outcomes after valvular surgery. Surgical Infections, 18(3), 299-302. https://doi.org/10.1089/sur.2016.029

Levine, J. S., \& Ahnen, D. J. (2006). Adenomatous polyps of the colon. New England Journal of Medicine, 355(24), 2551-2557.

http://www.nejm.org/doi/full/10.1056/NEJMcp063038

Li, J. S., Sexton, D. J., Mick, N., Nettles, R., Fowler Jr, V. G., Ryan, T., ... \& Corey, G. R. (2000). Proposed modifications to the Duke criteria for the diagnosis of infective endocarditis. Clinical Infectious Diseases, 30(4), 633-638. https://doi.org/10.1086/313753

Lieberman, D., Moravec, M., Holub, J., Michaels, L., \& Eisen, G. (2008). Polyp size and advanced histology in patients undergoing colonoscopy screening: implications for CT colonography. Gastroenterology, 135(4), 1100-1105.

https://doi.org/10.1053/j.gastro.2008.06.083
McCoy, W. C., \& Mason 3rd, J. M. (1951). Enterococcal endocarditis associated with carcinoma of the sigmoid; report of a case. Journal of the Medical Association of the State of Alabama, 21(6), 162-166. https://pubmed.ncbi.nlm.nih.gov/14880846/

Murdoch, D. R., Corey, G. R., Hoen, B., Miró, J. M., Fowler, V. G., Bayer, A. S., ... \& International Collaboration on Endocarditis-Prospective Cohort Study (ICE-PCS) Investigators. (2009). Clinical presentation, etiology and outcome of infective endocarditis in the 21st century: the International Collaboration on Endocarditis-Prospective Cohort Study. Archives of Internal Medicine, 169(5), 463-473. https://doi.org/10.1001/archinternmed.2008.603

Pasquereau-Kotula, E., Martins, M., Aymeric, L., \& Dramsi, S. (2018). Significance of Streptococcus gallolyticus subsp. gallolyticus association with colorectal cancer. Frontiers in Microbiology, 9, 614. https://doi.org/10.3389/fmicb.2018.00614

Pericàs, J. M., Corredoira, J., Moreno, A., García-País, M. J., Falces, C., Rabuñal, R., ... \& Miró, J. M. (2017). Relationship between Enterococcus faecalis infective endocarditis and colorectal neoplasm: preliminary results from a cohort of 154 patients. Revista Española de Cardiología (English Edition), 70(6), 451-458. https://doi.org/10.1016/j.recesp.2016.09.055

Pizzi, M. N., Roque, A., Fernández-Hidalgo, N., CuéllarCalabria, H., Ferreira-González, I., Gonzàlez-Alujas, M. T., .. \& Tornos, P. (2015). Improving the diagnosis of infective endocarditis in prosthetic valves and intracardiac devices with $18 \mathrm{~F}$ fluordeoxyglucose positron emission tomography/computed tomography angiography: initial results at an infective endocarditis referral center. Circulation, 132(12), 1113-1126. https://doi.org/10.1161/circulationaha.115.015316

Rusniok, C., Couvé, E., Da Cunha, V., El Gana, R., Zidane, N., Bouchier, C., ... \& Glaser, P. (2010). Genome sequence of Streptococcus gallolyticus: insights into its adaptation to the bovine rumen and its ability to cause endocarditis. Journal of bacteriology, 192(8), 2266-2276. https://doi.org/10.1128/JB.01659-09

Schlegel, L., Grimont, F., Ageron, E., Grimont, P. A., \& Bouvet, A. (2003). Reappraisal of the taxonomy of the Streptococcus bovis/Streptococcus equinus complex and related species: description of Streptococcus gallolyticus subsp. gallolyticus subsp. nov., S. gallolyticus subsp. macedonicus subsp. nov. and S. gallolyticus subsp. pasteurianus subsp. nov. International Journal of Systematic and Evolutionary Microbiology, 53(3), 631-645. https://doi.org/10.1099/ijs.0.02361-0 
Schreuders, E. H., Ruco, A., Rabeneck, L., Schoen, R. E., Sung, J. J., Young, G. P., \& Kuipers, E. J. (2015). Colorectal cancer screening: a global overview of existing programmes. Gut, 64(10), 1637-1649. https://doi.org/10.1136/gutjnl-2014-309086

Sillanpää, J., Nallapareddy, S. R., Singh, K. V., Ferraro, M. J., \& Murray, B. E. (2008). Adherence characteristics of endocarditis-derived Streptococcus gallolyticus ssp. gallolyticus (Streptococcus bovis biotype I) isolates to host extracellular matrix proteins. FEMS microbiology letters, 289(1), 104109. https://doi.org/10.1111/j.15746968.2008.01378.x

Strum, W. B. (2016). Colorectal adenomas. New England Journal of Medicine, 374(11), 1065-1075. https://doi.org/10.1056/nejmra1513581

Takamura, N., Kenzaka, T., Minami, K., \& Matsumura, M. (2014). Infective endocarditis caused by Streptococcus gallolyticus subspecies pasteurianus and colon cancer. BMJ Case Report, 2014, 8-11. https://doi.org/10.1136/bcr-2013-203476

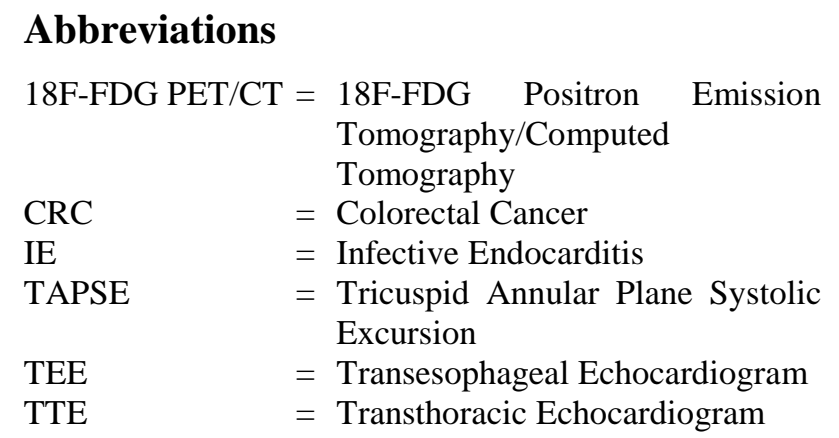

